УДК 811.11-112

DOI: 10.33184/YVDK-2021-04-30.53

Д.Р. Мухаметзянова (студ. 3-го курса СФ БаиГУ,

2. Стерлитамак),

Р.Х. Каримова (канд. филол. н. СФ БаиГУ, г. Стерлитамак)

\title{
ЛЕКСИКО-СЕМАНТИЧЕСКАЯ ГРУППА ГЛАГОЛОВ МЫШЛЕНИЯ В НЕМЕЦКОМ ЯЗЫКЕ
}

В статье приводится анализ лекаико-семантической группы глаголов мьшиления немеикого языка. В качестве чентрального компонента исследования взят глагол «denkеп». Результать проведенного анализа позволили сделать вылводы, касаюичеся семантпческих характеристик немеиких глагольных синонимов, относяиихсяк глаголаминтеллектуальной деятельности.

Ключевые слова: глаголь мьпиения, лексико-семантическая группа, значение, семантика

The article analyzes the lexical and semantic group of verbs of thinking in the German language. The verb «denken» is taken as the central component of the study. The results of the analysis allowed us to draw conclusions conceming the semantic characteristics of the German verbal synonyms related to the verbs of intellectual activity.

Keywords: verbs of thinking, lexical-semantic group, meaning, semantics

На сегодняшний день вопрос изучения глагольной семантики в разных языках является одной из наиболее актуальных тем для исследования. Изучая данную грамматическую категорию, мы не только выявляем отдельные оттенки слов, но и раскрываем их сущности в целом, благодаря чему возможно более точное использование глагола в речи.

Для того чтобы правильно построить речевое высказывание, нам необходимо знать, какой глагол больше подходит для употребления, исходя из определенного контекста. Так, очень часто изучающие иностранный язык путают глаголы, которые являются частью определенной лексико-семантической группы, потому что не учитывают их значения.

Нередко ошибки возникают при использовании слов из лексико-семантической группы глаголов мышления, которые в 
немецком языке чаще всего представлены такими глаголами, как «denken» и «überlegen».

Актуальность темы исследования обусловлена устойчивым интересом к проблемам состава и границы лексикосемантической группы глаголов мышления, а также особенностям значений ее составляющих.

Целью работы является анализ семантики основных компонентов данной группы. Следовательно, в качестве объекта исследования можно выделить лексико-семантическую группу глаголов мышления, а предмета - различные оттенки значений представленных глаголов.

Традиционно под лексико-семантической группой понимают «множества слов, в значениях которых представлена хотя бы одна общая (категориальная) сема» [Зеленецкий 2003: 276]. Иными словами, это группа слов, объединенных близкими или однородными лексическими значениями.

В ЛСГ представлен семантический минимум слов, состоящий из синонимических пар или рядов. Однако представленные в нем глаголы могут отличаться своим значением в зависимости от контекста, поэтому они могут быть по-разному эмоционально окрашены.

Рассмотрим лексико-семантическую группу мышления. В качестве центрального компонента мы взяли глагол «denken», который наиболее обобщенно передает понятие мышления в немецком языке. Согласно электронному словарю DWDS, он обозначает все уровни и формы высшей мозговой деятельности человека [4]. При этом выделяются следующие значения, которые непосредственно связаны с интеллектуальной активностью человека:

1. Verstandesarbeit leisten, etw. überlegen;

2. gesinnt sein;

3. etw. beabsichtigen, im Sinne haben;

4. etw. meinen, glauben;

5. sich geistig in etw. versetzen (sich in etw. denken);

6. sich jmdn., etw. (als jmdn., etw., in bestimmter Weise) vorstellen (sich jmdn., etw. (als jmdn., etw., in bestimmter Weise) denken);

7. sich an jmdn., etw. erinnern, jmds., einer Sache gedenken (an etw., jmdn. denken); 
8. etw., jmdn. in den Mittelpunkt seines Strebens stellen (an etw., jmdn. denken;

9. eine Meinung von etw., jmdm. haben, über etw., jmdn. urteilen (in bestimmter Weise von etw., jmdm., über etw., jmdn. denken) [4].

В другом известном словаре немецкого языка Duden мы находим сходные значения глагола «denken»:

1. die menschliche Fähigkeit des Erkennens und Urteilens anwenden; mit dem Verstand arbeiten; überlegen;

2. eine bestimmte Gesinnung haben, gesinnt sein;

3. annehmen, glauben, vermuten, meinen;

4. eine bestimmte Meinung von etwas haben, etwas von etwas halten;

5. sich etwas (in bestimmter Weise) vorstellen;

6. sich erinnern, gedenken;

7. seine Gedanken, sein Interesse auf jemanden, etwas richten;

8. eine bestimmte Absicht haben, etwas Bestimmtes vorhaben [3].

Исходя из данных значений, выделенных в словарях DWDS и Duden, можно сделать вывод, что глагол «denken» может быть использован для выражения:

1. мыслительной активности;

2. определенного настроя к чему-либо или кому-либо;

3. собственного мнения;

4. человеческой способности к размышлению и обдумыванию;

5. представления чего-либо или кого-либо определенным образом (в этом случае глагол становится возвратным);

6. процесса воспоминания (вместе с предлогом «ап»);

7. способности сосредоточиться своими мыслями на чем-то или на ком-то (в сочетании с предлогом «ап»);

8. процесса думать по поводу чего-либо или кого-либо, а также иметь мнение относительно чего-то или кого-то.

Следовательно, у общей категориальной семы «denken», которая является главным компонентом в лексико-семантической группе глаголов мышления, на основе вышеперечисленных значений можно построить восемь синонимических рядов.

В словаре Brockhaus Wahrig в качестве основных синонимов к первому значению семы «denken», связанному с непосредственной мыслительной деятельностью человека, выделяются такие глаголы, как «überlegen», «bedenken», «überdenken», «nachdenken», «durchdenken» и «sich fragen» [Wahrig 2013: 216]. При этом выраженный с их помощью процесс 
мышления обычно также имеет определенную направленность (über etw. nachdenken, etw. überlegen - думать о чем-то).

Синонимическая пара «gesinnt sein», «eingestellt sein» построена на основе значения настроенности к чему-то или комуто. Кроме того, словарь DWDS приводит определенные прилагательные, с которыми обычно используется глагол «denken» в данном значении. К ним относят: «edel», «groß», «rechtlich», «kleinlich» и «gemein» [4].

Следующее семантическое поле подразумевает под собой выражение мнения или заключения. В словаре Wahrig мы находим синонимы, которые можно использовать вместо глагола «denken», когда человек считает или полагает, что что-то является верным или неверным, а также высказывается по определенной теме: «meinen», «glauben», «annehmen», «vermuten», «finden», «der Meinung/Ansicht sein», «dafürhalten», «halten für», «erachten», «ermessen» и «auffassen» [Wahrig 2013: 217].

Большое количество глаголов относятся к семантике «размышлять» и «обдумывать», особенно перед принятием какого-либо решения. В качестве примеров можно привести глаголы «überlegen», «überdenken», «durchdenken», «sinnen», «sinnieren», «rätseln» «reflektieren», «meditieren», «seinen Geist anstrengen» и «sich den Kopf zerbrechen» [Wahrig 2013: 217]. В словаре Duden данное значение приводится также у глаголов «nachgrübeln», «nachdenken» и «nachsinnen» [3]. Более того, глагол «überlegen» может встречаться и среди синонимичного ряда глаголов с семантикой «взвешивать», «обдумывать», к которым относят «wägen», «abwägen», «erwägen» и «bedenken» [Wahrig 2013: 217].

Со значением «представить какое-либо явление или человека в определенном образе» словарь Wahrig синонимов не приводит. Однако согласно словарю DWDS глагол «sich denken» может быть заменен схожими по смыслу словосочетаниями «sich vorstellen» и «im Sinn haben» [4].

На основе значения «вспоминать», представленного глаголом «denken» в сочетании с предлогом «an», можно построить следующий синонимический ряд слов: «sich erinnern», «zurückschauen», «zurückblicken», «gedenken» и «sich zurückerinnern» [Wahrig 2013: 217]. Кроме того, сам глагол «denken an» может быть употреблен и в семантике постоянного 
раздумья о чем-либо или о ком-либо. А в качестве синонимов приводятся такие глаголы, как «vorschweben», «nachdenken» и «bedenken».

Глагол «denken» с предлогом «über» также имеет свой синонимический ряд, представленный на основе значения, непосредственно связанного с мнением или суждением человека относительного чего-либо или кого-либо. В такой семантике глагол DWDS предлагает к использованию следующую пару словосочетаний: «јеmandes Meinung sein» и «finden dass» [4].

Из этого следует, что к каждому значению глагола мышления «denken» можно выделить определенные семантические группы с синонимами. Результат исследования представлен в таблице 1:

\begin{tabular}{|c|c|}
\hline Значение & Глаголы-синонимы \\
\hline «думать» & $\begin{array}{c}\text { «überlegen», «bedenken», «überdenken», } \\
\text { «nachdenken», «durchdenken», «sich } \\
\text { fragen» }\end{array}$ \\
\hline «быть настроенным» & «gesinnt sein», «eingestellt sein» \\
\hline «выражать мнение» & $\begin{array}{c}\text { «meinen», «glauben», «annehmen», } \\
\text { «vermuten», «finden», «der } \\
\text { Meinung/Ansicht sein», «dafürhalten», } \\
\text { «halten für», «erachten», «ermessen», } \\
\text { «auffassen» }\end{array}$ \\
\hline «размышлять» & $\begin{array}{c}\text { «überlegen», «überdenken», } \\
\text { «durchdenken», «sinnen», «nachgrübeln», } \\
\text { «nachdenken», «nachsinnen», «sinnieren», } \\
\text { «rätseln» «reflektieren», «meditieren», } \\
\text { «seinen Geist anstrengen», «sich den Kopf } \\
\text { zerbrechen» }\end{array}$ \\
\hline «представлять» & «sich vorstellen», «im Sinn haben» \\
\hline «вспоминать» & $\begin{array}{c}\text { «sich erinnern», «zurückschauen», } \\
\text { «zurückblicken», «gedenken», «sich } \\
\text { zurückerinnern» } \\
\end{array}$ \\
\hline $\begin{array}{l}\text { «сосредоточенно } \\
\text { думать» }\end{array}$ & $\begin{array}{c}\text { «vorschweben», «nachdenken», } \\
\text { «bedenken» }\end{array}$ \\
\hline $\begin{array}{c}\text { «иметь мнение/судить } \\
\text { о чем-либо» }\end{array}$ & «jemandes Meinung sein», «finden dass» \\
\hline
\end{tabular}


Таблииа 1. Лексико-семантическое поле глаголов мышления

Исходя из статистических данных, мы выявили их процентное соотношение:

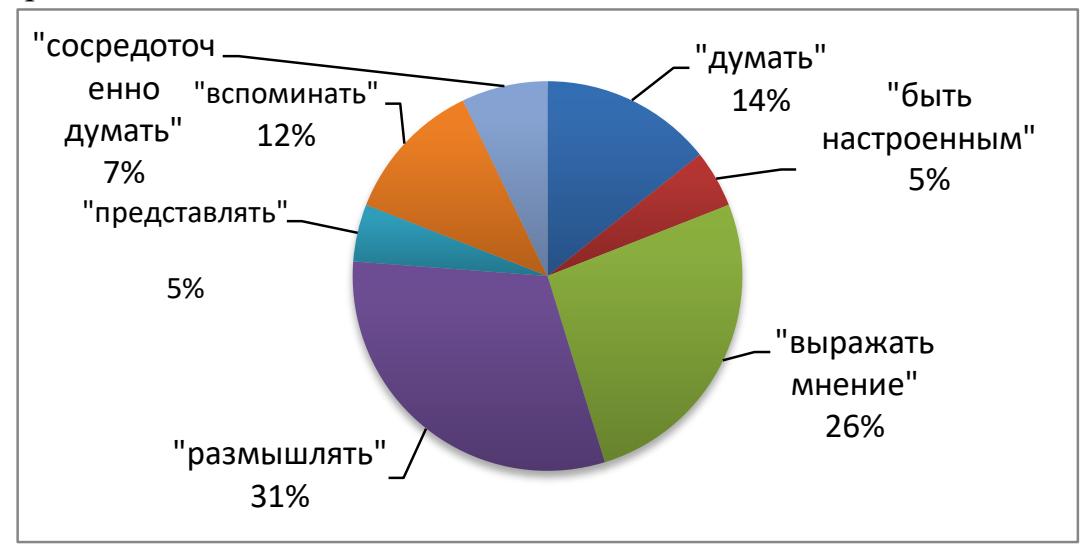

Рис 1.Процентнюе соотношениеглаголов мышления

Таким образом, наибольшее количество глаголов оказалось в группе со значением «размышляты) - 13 слов (31\%), дале, в семантике «выражать мнение), где представлено 11 слов (26 \%). Меныше глаголов найдено со значениями «думать» (6 слов, $14 \%$ ), «вспоминать» (5 слов, $12 \%$ ) и «сосредоточенно думать» (3 слова, 7 \%). Всего по 2 синонима выделяется в группах «быть настроенным», «представляты» и «судиты» (5\%).

На основе проведенного анализа можно сделать вывод, что данная лексико-семантическая группа располагает многообразными видами синонимических рядов глаголов, которые также могуг менять свюе значение в различном контексте.

\section{ЛИТЕРАТУРА}

1. Зеленецкий АЛ. Теория немецкого языкознания: Учеб. пособие дпя студ. лингв. ун-тов и фак. ин. яз. высш. пед. учеб. заведений. -М.: Академия, 2003. $-400 \mathrm{c}$.

2. Wahrig Synonymwörterbuch - Gütersloh, München: Wissen Media in der Media ONEGmbH, 2013.-1024S.

3. Duden - Deutsches Universalwörterbuch [Электронный ресурc]. - URL : http://www.duden.de (дата обращения: 14.04.2021).

4. DWDS - Digitales Wörterbuch der deutschen Sprache [Электронный ресурс]. URL: https://www.dwds.de/ (дата обращения: 14.04.2021).

(С) Мухамегзянова ДР., Каримова Р.Х., 2021 г. 